\title{
Generation of Flavors and Fragrances Through Biotransformation and De Novo Synthesis
}

\author{
Adelaide Braga $^{1} \cdot$ Carlos Guerreiro $^{1} \cdot$ Isabel Belo ${ }^{1}$ \\ Received: 8 May 2018 / Accepted: 10 September 2018 / Published online: 19 September 2018 \\ (C) Springer Science+Business Media, LLC, part of Springer Nature 2018
}

\begin{abstract}
Flavors and fragrances are the result of the presence of volatile and non-volatile compounds, appreciated mostly by the sense of smell once they usually have pleasant odors. They are used in perfumes and perfumed products, as well as for the flavoring of foods and beverages. In fact the ability of the microorganisms to produce flavors and fragrances has been described for a long time, but the relationship between the flavor formation and the microbial growth was only recently established. After that, efforts have been put in the analysis and optimization of food fermentations that led to the investigation of microorganisms and their capacity to produce flavors and fragrances, either by de novo synthesis or biotransformation. In this review, we aim to resume the recent achievements in the production of the most relevant flavors by bioconversion/biotransformation or de novo synthesis, its market value, prominent strains used, and their production rates/maximum concentrations.
\end{abstract}

Keywords Bioconversion $\cdot$ Biotransformation $\cdot$ De novo synthesis $\cdot$ Flavors $\cdot$ Fragrances

\section{Introduction}

Flavors and fragrances have a wide application in the food, feed, cosmetic, chemical, and pharmaceutical sectors (Vandamme 2003). Nowadays, they represent over a quarter of the world market for food additives and most of them are provided by extraction from natural sources or by traditional methods, as chemical synthesis. The specialized magazine Perfumer \& Flavorist has recently reported that the expected market for flavors and fragrances will reach US\$ 45.6 billion in 2018 ("http://www.perfumerflavorist.com/fragrance/ trends/Report-Global-Fragrances-Perfumes-Market-ToReach-456B-by-2018-197588241.html," n.d.) with a good growth rate over the next 5 years.

The most common processes to produce flavor compounds are the extraction from natural sources and the chemical synthesis. Nevertheless, extraction from plants has many disadvantages such as low concentration of the product of interest, seasonal variation, risk of plant diseases, stability of the compound, and trade restrictions. In

Isabel Belo

ibelo@deb.uminho.pt

1 CEB - Centre of Biological Engineering, University of Minho, Campus de Gualtar, 4710-057 Braga, Portugal fact, chemical synthesis still represents the cheaper technology for their production; however, it may require harsh conditions (toxic catalysts, high pressure and temperature, among others) and usually lack adequate regio- and enantio-selectivity to the substrate, resulting in a mixture of products. Additionally, the compounds generated are labelled as "artificial" or "nature identical", decreasing their economic value (Longo and Sanromán 2006; Vandamme 2003). An increasing in the interest on the biotechnological production and use of flavor compounds of (micro) biological origin is observed, since the products obtained may be labeled as "natural" (Vandamme 2003; Vandamme and Soetaert 2002). In the USA and according to European regulations (e.g., CFR 1990 and EEC 1334/2008), compounds isolated from natural resources or obtained by microbial or enzymatic processes involving precursors isolated from nature are classified as "natural" (European Commission 2008; FDA 2013). Even though the low yields obtained in most of the reported biotechnological processes for flavor production, in some cases they are economically feasible. Some examples of commercial "natural" flavors biotechnologically produced are ethyl butanoate, 2 -heptanone, $\beta$ ionone, nootkatone, 1-octen-3-ol, 4-undecalactone, and vanillin (Berger 2009; Caputi and Aprea 2011). One of the main motivations for the microbial production of flavor compounds is its market price, which is normally far above 
their synthetic counterparts, but usually lower than those extracted from nature. For example: synthetic vanillin has a price of around US\$ $11 \mathrm{~kg}^{-1}$, natural vanilla flavor extracted from fermented pods of Vanilla orchids costs US\$ $1200-4000 \mathrm{~kg}^{-1}$, while "biotech vanillin" is sold for a price of around US\$1000 kg-1 (Schrader et al. 2004; Xu et al. 2007). Equivalent data are also observed for other aroma compounds, such as $\gamma$-decalactone (synthetic $=$ US $\$$ $150 \mathrm{~kg}^{-1}$; natural $=$ US $\$ 6000 \mathrm{~kg}^{-1}$; "biotech" $=$ US $\$$ $300 \mathrm{~kg}^{-1}$ ) and ethyl butyrate (synthetic $=\mathrm{US} \$ 4 \mathrm{~kg}^{-1}$; natural = US\$ $5000 \mathrm{~kg}^{-1}$; "biotech" = US\$ $\left.180 \mathrm{~kg}^{-1}\right)$ (Dubal et al. 2008). Flavor compounds can be biotechnologically produced in two basic ways: through de novo synthesis or by biotransformation. De novo synthesis refers to the production "from the new", i.e., the synthesis of substances from simple building block molecules (sugars, amino acids, nitrogen salts, minerals, among others), which will be metabolized by organisms to form a different and complex structure. Biotransformations, in turn, are single reactions catalyzed enzymatically (as pure enzymes or within microbial cells). Therefore, the substrate is metabolized by the organism (usually a breakdown or an oxidation/reduction process) in a single (bioconversion) or a few (biotransformation) reactions to produce a structurally similar molecule (Bicas et al. 2015). The production of aroma compounds by de novo synthesis usually generates a mixture of products, whose maximal concentrations are normally below $100 \mathrm{mg} \mathrm{L}^{-1}$ (Bicas et al. 2015). Therefore, biotransformations have higher potential for the production of "bioflavors" on a commercial scale (Bicas et al. 2015).

\section{Biotechnological Production of Flavors}

Considering the disadvantages of chemical production, regarding the quality of the product, health and environmental issues and the inability of natural production at industrial scale, the need to address an alternative way for flavor production through low-cost and environmentally friendly processes became crucial. Consumer perception that everything natural is better is causing an increase demand for natural flavor additives and biotechnological routes may be, if they exclude any chemical steps, a way to get natural products (Longo and Sanromán 2006). De novo synthesis should be therefore used for complex targets or product mixtures, whereas bioconversions/biotransformations are able to carry out single-step processes. In general, microorganisms are able to produce a wide range of flavor compounds by de novo synthesis. However, the production levels are very poor, and thus constitute a limit for industrial exploitation.

Table 1 presents some of the most relevant flavour and fragrance compounds that can be produced through microbial biotransformation or by de novo synthesis.

\section{Bioconversion/Biotransformation}

Bioconversions/biotransformations can be cheaper, greener, and more direct than their chemical analogues. Since the first discoveries of microbial production of blue cheese-note compounds in 1950 (Patton 1950), several bioflavor synthetic paths have been unveiled and exploited throughout the decades. In the next topic, microbial production of today's key flavor compounds in food, beverage, and cosmetic industry will be addressed.

\section{Phenolic Aldehydes}

The most important flavors and fragrances from the class of phenolic aldehydes are anisaldehyde and some derivatives of protocatechu aldehyde (3,4-dihydroxybenzaldehyde), such as vanillin, veratraldehyde, and heliotropin. In fact, vanillin is one of the most popular flavors in the world. Vanillin is the primary component of the extract of the vanilla bean. These flavors can be extracted from the beans of Vanilla species such as Vanilla planifolia and Vanilla tahitensis (Gallage et al. 2014); however, total world consumption of vanilla beans has been affected due to its very high price (US\$ 20 per $\mathrm{kg}$ in 2010 and US\$ 500 in 2016) (Berger 2007; Eurovanille 2017). In 2017, the record price of vanilla beans was due to a cyclone that hit Madagascar (world's main producer of approximately US\$ 100 million) and consequently destroyed the plant cultures. This compound is not only widely used as flavor enhancer in sweet foods such as ice creams, cookies, or cakes, but also in soft beverages, cosmetics, or as precursor for pharmaceutical preparations, and as food preservative. Also, synthetic vanillin is used in the production of deodorants, air fresheners, cleaning products, antifoaming agents, or herbicides (Ramachandra Rao and Ravishankar 2000; Sinha et al. 2008; Walton et al. 2003).

Over the years, most of the studies extensively addressed the biotransformation of lignin, aromatic amino acids, phenolic stilbenes, ferulic acid (FA), vanillic acid, isoeugenol, or curcumin for the vanillin production, in a concentration range of 0.13 to $32.5 \mathrm{~g} \mathrm{~L}^{-1}$ (Huang et al. 1993; Kaur and Chakraborty 2013; Priefert et al. 2001; Zhao et al. 2005). In 2010, Tilay et al. (2010) investigated the effects of media composition and environmental factors such as $\mathrm{pH}$ on vanillin production from FA by one-step biotransformation using fungus Pycnoporous cinnabarinus. In optimized conditions, vanillin production reached a maximum of $126 \mathrm{mg} \mathrm{L}^{-1}$. Regarding FA biotransformation, in 2016, Fleige et al. (2016) used a metabolic engineered strain, Amycolatopsis sp. ATCC 39116, in a fermentative process where vanillin degradation was decreased in $90 \%$ through the deletion of vanillin dehydrogenase gene $(v d h)$. Moreover, vanillin production was enhanced by constitutive expression of feruloyl CoA synthetase $(f c s)$ and enoyl CoA hydratase (ech), resulting 
Table 1 Classification and chemical structure of some of the most relevant flavor and fragrance compounds produced by microbial biotransformation or by de novo synthesis

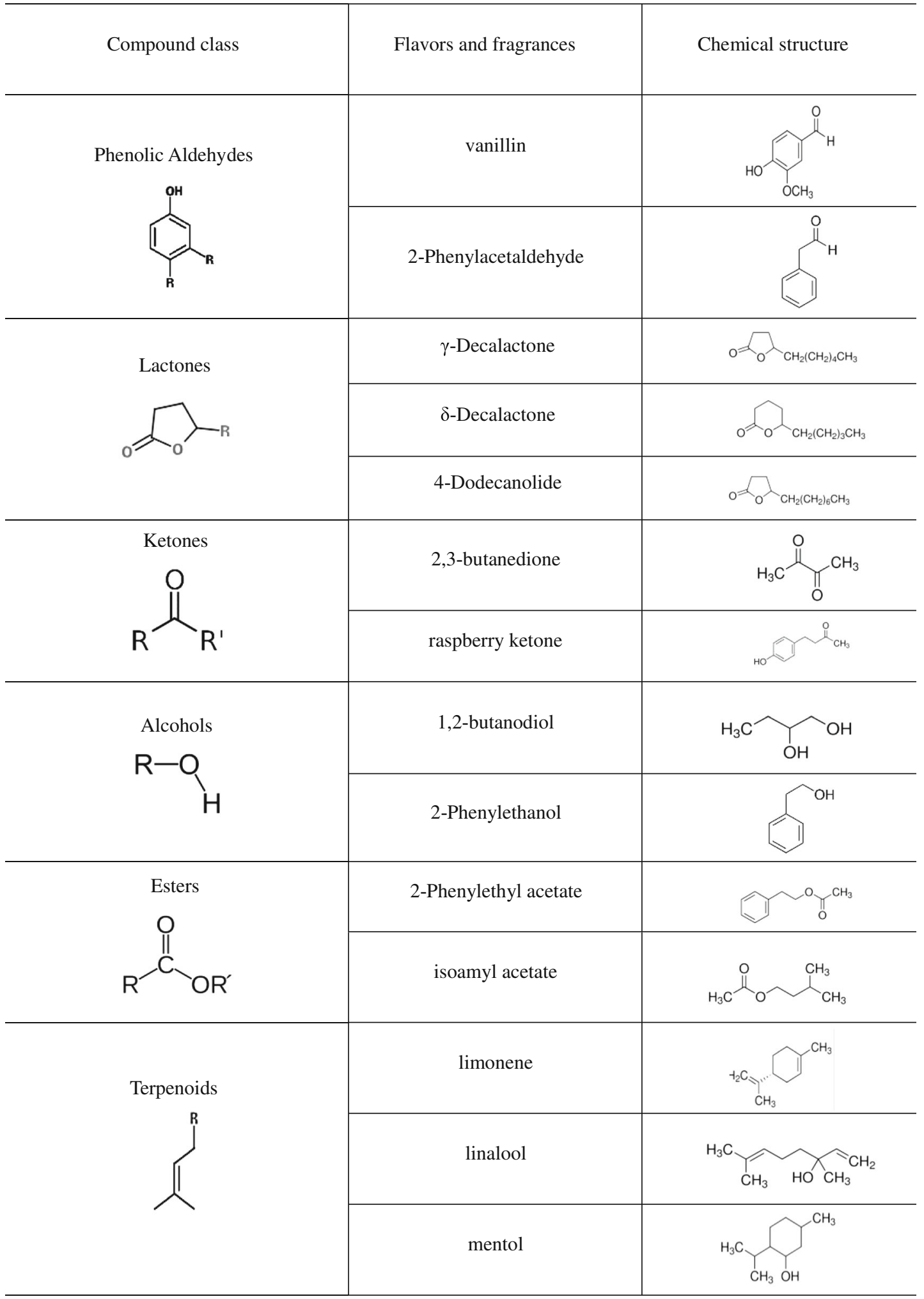

in a maximum molar yield of $94.9 \%$ and a vanillin concentration of $22.3 \mathrm{~g} \mathrm{~L}^{-1}$ (the highest value obtained with this strain so far) (Fleige et al. 2016). Recently, Furuya et al. (2017) demonstrated that a coenzyme-independent cascade consisting of the ferulic acid decarboxylase (Fdc) and coenzymeindependent oxygenase (Cso2) could be applied in an 
immobilized enzyme process for vanillin production from FA. Using this approach, vanillin concentrations between 365 and $578 \mathrm{mg} \mathrm{L}^{-1}$ were achieved in 24-h biotransformation cycles. This is an innovative study since production through immobilized enzymes had never been previously performed in this process (Furuya et al. 2017). Moreover, Furuya's research group had previously studied vanillin production from FA via 4-vinylguaiacol in a new two-pot reaction bioprocess on a flask scale (Furuya et al. 2015). In a first stage, E. coli cells expressing $F d c$ rapidly decarboxylated $14.56 \mathrm{~g} \mathrm{~L}^{-1}$ of FA and converted into 4-vinylguaiacol. After that, cells were removed and new E. coli cells expressing Cso 2 were added, beginning the second stage. Using this strategy, a final titer of $7.8 \mathrm{~g} \mathrm{~L}^{-1}$ was achieved, which is the highest known level using recombinant cells of E. coli (Furuya et al. 2015).

Bioconversion of isoeugenol into vanillin was fairly studied by Ashengroph et al. (2012) in the recent years. Firstly, in 2011, this bioconversion was studied using Psychrobacter sp. CSW4 strain. A maximum vanillin titer of $1.28 \mathrm{~g} \mathrm{~L}^{-1}$ was achieved from an initial isoeugenol concentration of $10 \mathrm{~g} \mathrm{~L}^{-1}$, after a $48 \mathrm{~h}$ reaction under a resting cell system. However, the best molar yield (16.4\%) was achieved after an 18-h reaction when an initial substrate concentration of $1 \mathrm{~g} \mathrm{~L}^{-1}$ was used (Ashengroph et al. 2012). This was the first evidence of isoeugenol bioconversion into vanillin by the genus Psychrobacter. A couple years later, these results were optimized with the implementation of Taguchi design and response surface methodology (Ashengroph et al. 2013), allowing to obtain a vanillin titer of $2.19 \mathrm{~g} \mathrm{~L}^{-1}$ after $24 \mathrm{~h}$, from an initial isoeugenol concentration of $6.5 \mathrm{~g} \mathrm{~L}^{-1}$. A few years later, Ashengroph and Amini (2017) converted isoeugenol into vanillin under a resting cell system. Trichosporon asahii MP24 cells converted $5 \mathrm{~g} \mathrm{~L}^{-1}$ of isoeugenol to a final vanillin titer of $2.4 \mathrm{~g} \mathrm{~L}^{-1}$ after $32 \mathrm{~h}$; however, vanillin reconsumption was observed for this microbial species.

\section{Terpenes}

Terpenoids or isoprenoids, are the most diversified class of natural compounds synthesized from plants, animals, or microorganisms, reaching a panoply of 40,000 different compounds (Rohdich et al. 2005; Withers and Keasling 2007). One of the most studied precursors in biotechnological monoterpenoid production is limonene, since it can be derivatized to a variety of value-added compounds, such as carvone, carveol, perillyl alcohol ( $\mathrm{POH})$, terpineols, menthol, and pinenes (Duetz et al. 2003; Maróstica and Pastore 2007). Limonene can be produced by one key enzyme, limonene synthase (LS), by catalysis of intramolecular cyclization of geranyl pyrophosphate (GPP) (Behrendorff et al. 2013; Jongedijk et al. 2015). Usually it is used as fragrance ingredient in cleaning products and perfumes or in citrus-flavored products such as candies and drinks (Duetz et al. 2003). It has a pleasant orange or citrus-like odor and is currently produced as a side product from the citrus juice industry (citrus oil can contain 70-98\% D-limonene), reaching 60,000 tons per year (Ciriminna et al. 2014). However, a few years ago, citrus oil availability has been affected in Brazil by a bacterial disease, resulting in a decreased yield and increasing prices (Hodges and Spreen 2015). Currently, limonene is sold at US\$ 9-10 per kilogram, while one decade ago manufacturers were paying as low as US\$ 0.4 per kilogram (Ciriminna et al. 2014; Lange 2015). Therefore, there has been constant fluctuation in availability and quality in plant-based and chemical production, thus it is important to find biotechnological alternatives (Jongedijk et al. 2016).

In 2014, Willrodt et al. (2014) achieved the highest ever reported L-limonene titer of $1.35 \mathrm{~g} \mathrm{~L}^{-1}$ by a recombinant microbial biocatalyst (E. coli BL21). Biotransformation was carried out in a 3.1-L stirred tank reactor (STR) in a two-liquid phase fed-batch setup. This recombinant strain possessed two functional plant genes: expression vector $\mathrm{pBAD}$ :LS and pET24:AGPPS2 which were equipped with the truncated and codon-optimized genes for LS and GPP synthase 2 (AGPPS2) (Willrodt et al. 2014). The limonene biosynthetic pathway in the yeast Yarrowia lipolytica was first reported by Cao et al. (2016) by heterologous expression of codonoptimized neryl diphosphate synthase 1 (NDPS1) and LS. DLimonene titer of $23.56 \mathrm{mg} \mathrm{L}^{-1}$ was the highest ever reported in yeasts, thus proving this species to be a solid platform for overproduction of limonene derivates or even other terpenoids.

\section{Alcohols}

Alcohols are produced by the normal metabolism of the microorganisms as a result of amino acid catabolism. These compounds, such as 2-butanol, 1,2-butanodiol, and 2phenylethanol (2-PE), possess unique organoleptic properties and are important flavor compounds in the food industry.

One of the most relevant flavor-alcohols is the 2-PE, an aromatic alcohol with a delicate fragrance of rose petals (Burdock 2010) widely applied in diverse types of products, such as perfumes, cosmetics, pharmaceuticals, foods, and beverages (Carlquist et al. 2015). Furthermore, 2-PE can be used as raw material to produce other important flavor compounds, such as 2-phenylethylacetate (a high-value aromatic ester (Etschmann et al. 2002) and a potential fuel molecule (Kang et al. 2014), phenylacetaldehyde (flavor compound), and phydroxphenylethanol (used in pharmaceutical and fine chemical industries) (Guo et al. 2017). The economic importance of 2-PE is quite significant; in 1990 it was reported that the 2-PE global market was estimated at 7000 tones, with 6000 tons used for fragrances, 10 tons for flavor applications, and 990 tons for synthesis of reaction products like esters (Etschmann et al. 2002). With the current available 
information, the global production of 2-PE is estimated at 10,000 tons per year and is dominated by chemical synthesis (Angelov and Gotcheva 2012; Hua and Xu 2011). In fact, microorganisms are able to produce 2-PE and other alcohols by normal metabolism as the result of amino acid catabolism, but the final concentration of the alcohol is very low (Carlquist et al. 2015). The biotechnological approach used to obtain natural 2-PE by bioconversion of L-phenylalanine (L-Phe), as the sole nitrogen source, via the Ehrlich pathway is the best and simple way to enhance the alcohol production (ÄYräpää 1965; Etschmann et al. 2002). Through the Ehrlich pathway, L-Phe is firstly converted to phenylpyruvate by transamination, which is then transformed to phenylacetaldehyde by decarboxylation; then, the derivative aldehyde is reduced to 2PE by dehydrogenation (Carlquist et al. 2015; Etschmann et al. 2002). Celinska et al. (2013) reported the ability of Y. lipolytica NCYC 3825 strain to produce 2-PE from L-Phe bioconversion achieving an aroma production of $1.98 \mathrm{~g} \mathrm{~L}^{-1}$.

Since yeasts are good candidates for 2-PE production from L-Phe bioconversion, considerable progresses have been achieved by applying different metabolic engineering strategies of related pathways (Guo et al. 2017; Kang et al. 2014; Wang et al. 2017). In yeasts, several genes are involved in the catabolism of L-Phe to 2-PE via Ehrlich pathway. Aro8p and Aro9p encoded by $A R O 8$ and $A R O 9$ were both characterized as aminotransferases that catalyze the transamination from LPhe to phenylpyruvate and the decarboxylation reaction was described with five genes (ARO10, THI3, PDC1, PDC5, and $P D C 6)$ encoding thiamine diphosphate-dependent decarboxylases (KDC) (Hazelwood et al. 2008). Kim et al. (2014a) reported the first metabolic engineering approach for 2-PE production in $S$. cerevisiae, overexpressing ARO9, $A R O 10$ e ARO80 genes. This study allowed genetic engineered strains to produce $0.45 \mathrm{~g} \mathrm{~L}^{-1}$ of 2-PE after $96 \mathrm{~h}$. The deletion of $A L D 3$ gene encoding for cytosolic aldehyde dehydrogenase that catalyzes phenylacetaldehyde oxidation to phenylacetate, was also tested. Being phenylacetate a competitor to 2-PE formation, the deletion of this gene increased the 2-PE production to $4.8 \mathrm{~g} \mathrm{~L}^{-1}$ (Kim et al. 2014a). These studies demonstrated the improvement of 2-PE production by overexpression of key enzymes in the Ehrlich pathway, providing new perspectives to enhance "natural" 2-PE production. Using an engineered E. coli strain, Guo et al. (2017) achieved a 2-PE production of $0.28 \mathrm{~g} \mathrm{~L}^{-1}$.

\section{Lactones}

Lactones are cyclic esters derived from lactic acid and they are constituents of a wide variety of essential oils and plant volatiles (Longo and Sanromán 2006; Waché et al. 2002). They are well-known for their great variety of taste and aroma (peach, pineapple, apricot, raspberry, strawberry, mango, papaya, cream, coconut, and nutt-like), reaching a production of hundreds of tons per year (Huang and Schwab 2011). The most important lactones are five- and six-membered rings, $\gamma$ - and $\delta$-lactones, respectively, with equal or less 12 carbons. It includes compounds such as 4-dodecanolide (coconut-fruity like) (Cheetham 2007; Gocho et al. 1995), 4-decanolide/ $\gamma$ decalactone (peach-like) (Schrader et al. 2004), 4-octanolide (sweet hearbaceous coconut-like) (Cardillo et al. 1990), 5dodecanolide (fruit-oily peach-like) (Gocho et al. 1998), 5decanolide/ $\delta$-decalactone (creamy-coconut peach-like) (Surburg et al. 2006), and 6-pentyl- $\alpha$-pyrone (6PP, strong coconut-like) (Collins and Halim 1972). Currently, lactone production is mainly achieved by chemical synthesis from keto acids; however, biotechnological production of $\gamma$ decalactones (GDL) and $\delta$-decalactones (DDL) is growing due to their natural/GRAS label reaching values between US\$ 1400 per $\mathrm{kg}$ and US\$ 6000 per $\mathrm{kg}$ (Hui 2006). In the decade of 1980, natural GDL was a rare flavor with a price exceeding US\$ 10,000 per kilogram; however, with its increasing biotechnological production over the years, prices dropped to US\$ 300 per kilogram (Schrader et al. 2004).

GDL is commonly used in cosmetic and perfume industry and can be obtained through $\beta$-oxidation of long-chain hydroxy fatty acids recurring to yeast cells (Barth 2013). Nowadays, Yarrowia lipolytica, a non-conventional oleaginous GRAS yeast, is gaining progressive relevance since it is capable of performing biotransformation of ricinoleic acid (RA) into GDL, using as RA sources, methyl ricinoleate (MR), or castor oil (CO). Y. lipolytica possesses a family of six acyl-CoA oxidases (Aox), encoded by POX1-6 gene family which plays an important role in $\beta$-oxidation of fatty acids (Pagot et al. 1997, 1998; Waché et al. 2001). This four-step process consists basically in two oxidation steps, one hydration and one cleavage reaction, which are catalysed by three enzymes. At each cycle, the compound gives rise to a two-carbon shorter metabolite and an acetyl (Nelson and Cox 2008). For years, Nicaud's research group has studied Aox family role and revealed Aox2 to be longchain specific ( $\mathrm{C} 18$ to $\mathrm{C} 10)$, while Aox3 is short-chain specific (C10 to C4) (Groguenin et al. 2004; Pagot et al. 1998; Waché et al. 2002; Waché et al. 2001), both with strong activity (Guo et al. 2012a, b; Pagot et al. 1998). Moreover, a few studies used modified strains of Y. lipolytica W29 (POX2 overexpressed and $P O X 3-5$ disrupted) and were able to produce more lactone without degrading it (Groguenin et al. 2004; Guo et al. 2012b).

In the last few years, Belo's research group has been extensively studying MR and CO biotransformation into GDL by $Y$. lipolytica by optimizing conditions in small flask cultures (Braga et al. 2012, 2013), in stirred-tank (Belo et al. 2015; Braga et al. 2015b; Braga and Belo 2015; Gomes et al. 2012) and airlift (Belo et al. 2015; Braga et al. 2015b) bioreactors. When these substrates were used, the RA rate release to the medium plays an important 
role in GDL production rate. Braga et al. $(2012,2013)$ pointed out the importance of extracellular lipases, namely the extracellular lipase produced by Y. lipolytica W29 and commercial lipases (Lipozyme TL IM), for the fast release of ricinoleic acid from castor oil and consequently faster formation of $\gamma$-decalactone. Nevertheless, this process is not the most adequate in an industrial point of view and the overexpression of Lip2 would bring the gap of this problem. Braga et al. (2015a) studied $\gamma$-decalactone production by the Y. lipolytica JMY3010 that has an additional copy of Lip 2 coding for the main extracellular lipase. Their results showed that the overexpression of Lip2 increased the $\gamma$-decalactone production rate.

Belo's research group studied GDL and 3-hydroxy- $\gamma$ decalactone (3-OH-GDL) production from MR (Gomes et al. 2012) and CO (Braga and Belo 2015) by Y. lipolytica W29 in STR bioreactor. The highest GDL and 3-OH-GDL titers, $6.7 \mathrm{~g} \mathrm{~L}^{-1}$ and $10 \mathrm{~g} \mathrm{~L}^{-1}$, were obtained in step-wise fed-batch strategy, using MR as substrate. Furthermore, similar productivities were observed when compared to batch experiments $\left(0.2 \mathrm{~g} \mathrm{~L}^{-1} \mathrm{~h}^{-1}\right)$, showing that both strategies are good alternatives for industrial processes. Additionally, Braga et al. (2015b) and Escamilla-García et al. (2014) studied lactone production, from $\mathrm{CO}$ and $\mathrm{MR}$, respectively, by Y. lipolytica $\mathrm{W} 29$ in airlift batch experiments. Braga et al. (2015b) observed a twofold increase in GDL production ( $3 \mathrm{~g} \mathrm{~L}^{-1}$ ) when compared to STR. On the other hand, Escamilla-García et al. (2014) concluded that higher aeration rates increased cell hydrophobicity and stimulated a tenfold increase in 3-OH-GDL production.

In these studies, GDL reconsumption was observed due to Aox 3 activity, which led to an increased 3-OH-GDL production. GDL reconsumption has been reported as an issue in older studies (Aguedo et al. 2005; Endrizzi et al. 1993; Waché et al. 2001). Braga et al. (2015a) compared lactone production profiles by Y. lipolytica W29 and two W29 mutants, MTLY40-2P (POX3-5 disrupted and POX2 overexpressed) and JMY3010. Similar productivities were observed in batch and fed-batch; however, the highest GDL titer ( $7 \mathrm{~g} \mathrm{~L}^{-1}$ ) was obtained by MTL40-2P in fed-batch strategy. Moreover, GDL reconsumption was avoided in mutant cultures.

The dissolved oxygen in the medium is one of the influencing factors in this type of bioprocess. It was shown that, under increased oxygen solubility, 3-OH-GDL and decenolide production in STR and airlift was favored due to higher 3hidroxyacil-CoA dehydrogenase activity (Aguedo et al. 2005; Escamilla-García et al. 2014; Gomes et al. 2007). On the other hand, under low aeration rates, an increased GDL production was observed due to lower Aox and dehydrogenase activities (Braga and Belo 2015; Garcia et al. 2007; García et al. 2009). However, higher GDL productivities were achieved at higher aeration rates (Braga and Belo 2015).
Recently, Rong et al. (2017b) studied RA biotransformation into GDL by S. cerevisiae MF013 in batch cultures performed in Erlenmeyer flasks. A maximum GDL concentration of $2.8 \mathrm{~g} \mathrm{~L}^{-1}$ was obtained after $60 \mathrm{~h}$ of biotransformation. The addition of $\gamma$-caprolactone and $\gamma$-octalactone to biotransformation medium suppressed GDL degradation as these compounds worked as competitive inhibitors for lactonase (the responsible enzyme for GDL degradation).

Soares et al. (2017) compared GDL production by Y. lipolytica CCMA 0357 and Lindera saturnus CCMA 0243, using glycerol and CO as substrate. Overall, L. saturnus CCMA 0243 achieved higher GDL concentrations in glycerol biotransformation media $\left(5.8 \mathrm{~g} \mathrm{~L}^{-1}\right.$ of GDL in $10 \%$ crude glycerol medium), while $Y$. lipolytica CCMA 0357 achieved better results in CO biotransformation media ( $3.5 \mathrm{~g} \mathrm{~L}^{-1}$ of GDL in $10 \% \mathrm{CO}$ medium).

Increasing product concentrations by genetic engineering improvements and process optimization may have issues such as yeast sensibility and product toxicity. Braga and Belo (2013) prevented the toxic effect of CO and GDL, when Y. lipolytica W29 were immobilized by DupUM®. A higher GDL titer $\left(1.6 \mathrm{~g} \mathrm{~L}^{-1}\right)$ and no GDL reconsumption were observed when using immobilized cells, compared to free cell cultures. In 2015, Zhao et al. (2015) studied GDL production from $\mathrm{CO}$ at flask scale with implementation of an ionic liquid as co-solvent and attapulgite to immobilize Y. lipolytica cells. This approach allowed to achieve a GDL titer of $8.05 \mathrm{~g} \mathrm{~L}^{-1}$. Later in 2017, GDL production from RA by $Y$. lipolytica has been improved by a porous starch delivery system (Rong et al. 2017a). This system simultaneously acted as dispersant to control RA release and a lactone adsorbent, which significantly decreased the risk of cell damage. A resulting GDL titer of $3.36 \mathrm{~g} \mathrm{~L}^{-1}$ was achieved from $25 \mathrm{~g} \mathrm{~L}^{-1}$ of RA.

\section{De Novo Synthesis}

Flavor and fragrance production by de novo synthesis uses the whole metabolism of the microorganism to produce a combination of flavor compounds, in contrast to the biotransformation, where a specific reaction(s) produce a major compound. Whole cells catabolize carbohydrates, fats, and proteins, and further convert the breakdown products into flavor components (Engels and Visser 1994; Jeon 1994). Nevertheless, under these conditions, only trace amounts of flavors (more complex compounds) are produced and this process is not very promising and economically viable for industrial production because of the low concentrations of produced flavors (Belin et al. 1992). Some of the most relevant flavor compounds obtained by means of de novo synthesis will be discussed below (Table 2). 
Table 2 Examples of flavor compounds obtained from microbial de novo synthesis

\begin{tabular}{|c|c|c|c|c|c|}
\hline Product & $\begin{array}{l}\text { Aroma } \\
\text { description }\end{array}$ & Host & Concentration & Process information & Reference \\
\hline \multirow[t]{5}{*}{ 2-Phenylethanol } & \multirow[t]{5}{*}{ Rose-like } & Y. lipolytica & $0.2 \mathrm{~g} \mathrm{~L}^{-1}$ & Shake flask & Celinska et al. (2013) \\
\hline & & K. marxianus & $1.3 \mathrm{~g} \mathrm{~L}^{-1}$ & Shake flask & Kim et al. (2014b) \\
\hline & & E. coli & $0.26 \mathrm{~g} \mathrm{~L}^{-1}$ & Shake flask & Kang et al. (2014) \\
\hline & & $\begin{array}{l}\text { E. sp. } C G M C C \\
5087\end{array}$ & $0.33 \mathrm{~g} \mathrm{~L}^{-1}$ & Shake flask & Zhang et al. (2014) \\
\hline & & K. lactis & $0.72 \mathrm{~g} \mathrm{~L}^{-1}$ & Shake flask & Jiang (1993) \\
\hline \multirow[t]{4}{*}{ Diacetyl } & \multirow[t]{4}{*}{ Buttery } & L. casei & $1.4 \mathrm{~g} \mathrm{~L}^{-1}$ & MRS medium & Nadal et al. (2009) \\
\hline & & L. lactis & $0.36 \mathrm{~g} \mathrm{~L}^{-1}$ & Skim milk medium & Guo et al. (2012a) \\
\hline & & E. aerogenes & $1.35 \mathrm{~g} \mathrm{~L}^{-1}$ & CMD medium & Zhao et al. (2009) \\
\hline & & $\begin{array}{l}\text { C. glabrata } \\
\text { DA-3 }\end{array}$ & $4.7 \mathrm{~g} \mathrm{~L}^{-1}$ & CMD medium & Gao et al. (2014) \\
\hline \multirow[t]{5}{*}{ Limonene } & \multirow[t]{5}{*}{ Orange-like } & \multirow[t]{5}{*}{ E. coli } & $5 \mathrm{mg} \mathrm{L}^{-1}$ & Steam distillation & $\begin{array}{l}\text { Alonso-Gutierrez et al. (2013); Carter et al. (2003); } \\
\text { Willrodt et al. (2014) }\end{array}$ \\
\hline & & & $430 \mathrm{mg} \mathrm{L}^{-1}$ & Dodecane organic phase & Alonso-Gutierrez et al. (2013) \\
\hline & & & $2.7 \mathrm{~g} \mathrm{~L}^{-1}$ & $\begin{array}{l}\text { Diisonoyl phthalate } \\
\text { organic phase }\end{array}$ & Willrodt et al. (2014) \\
\hline & & & $4 \mathrm{mg} \mathrm{L}^{-1}$ & Dodecane organic phase & Davies et al. (2014) \\
\hline & & & $1.48 \mathrm{mg} \mathrm{L}^{-1}$ & Dodecane organic phase & Behrendorff et al. (2013) \\
\hline \multirow[t]{3}{*}{ Vanilin } & \multirow[t]{3}{*}{ Vanilla } & \multirow[t]{2}{*}{ E. coli } & $119 \mathrm{mg} \mathrm{L}^{-1}$ & From glucose & Kunjapur et al. (2014) \\
\hline & & & $\begin{array}{l}97.2 \mathrm{mgL}^{-1} \\
13.3 \mathrm{mg} \mathrm{L}^{-1}\end{array}$ & $\begin{array}{l}\text { From 1-tyrosine } \\
\text { From xylose }\end{array}$ & Ni et al. (2015) \\
\hline & & S. cerevisiae & $500 \mathrm{mg} \mathrm{L}^{-1}$ & From glucose & Brochado et al. (2010) \\
\hline
\end{tabular}

\section{Terpenes}

Only a few works reported the terpene production by de novo synthesis. The production of citronellol, linalool, and geraniol, in the range of $50 \mu \mathrm{g} \mathrm{L}^{-1}$, has been reported by Drawert and Barton using Kluyveromyces lactis (Drawert and Barton 1978). The production of citronellol and geraniol by Ceratocystis moniliformis in bioreactor was also reported by Bluemke and Schrader (Bluemke and Schrader 2001). Limoneno can be produced by the methylerythritol 4phosphate or the mevalonate pathway in microorganisms. For its de novo production in microorganisms, the plant limonene synthase needs to be expressed (Carter et al. 2003). However, due to the low availability of geranyl diphosphate (GPP) in microorganisms, this strategy resulted in very low yields. The development of an economically viable process for limonene production in microorganisms could be achieved using metabolic engineering approaches to increase the availability of GPP. The highest yield of limonene, $2.7 \mathrm{~g} \mathrm{~L}^{-1}$, was achieved with a genetically manipulated $E$. coli (Willrodt et al. 2014). However, fewer reports on limonene production from yeasts are available and titers reached are still lower than the ones obtained in $E$. coli (from $56 \mu \mathrm{g} \mathrm{L}^{-1}$ to $4 \mathrm{mg} \mathrm{L}^{-1}$ ) (Behrendorff et al. 2013; Davies et al. 2014; Kiyota et al. 2014).

\section{Ketones}

Diacetyl (2,3-butanedione) is an important ketone flavor compound, responsible for the buttery aroma of many dairy products, and is used as an ingredient in the food industry (Zhang et al. 2015). It is naturally produced by various microorganisms, such as lactic acid bacteria, especially L. lactis biovar. diacetylactis, from citrate in co-fermentation with lactose, and Enterobacter aerogenes (Papagianni et al. 2007; Zhao et al. 2009). In these bacteria, pyruvate is condensated to $\alpha$ acetolactate by acetolactate synthase, and is subsequently converted to diacetyl in the presence of oxygen, through a nonenzymatic decarboxylation (Gao et al. 2014). A Lactococcus lactis mutant with low ALDC and lactate dehydrogenase activities was able to overproduce diacetyl with a final concentration of $0.52 \mathrm{~g} \mathrm{~L}^{-1}$ (Monnet et al. 2000). The highest yield of diacetyl synthesis has been demonstrated by Hugenholtz et al. (2000) with a yield of $0.16 \mathrm{~mol} \mathrm{~mol}^{-1}$ of glucose. Enterobacter aerogenes mutant strain was also able to produce $1.35 \mathrm{~g} \mathrm{~L}^{-1}$ of diacetyl with a molar yield of $0.04 \mathrm{~mol} \mathrm{~mol}^{-1}$ (Zhao et al. 2009). More recently, Candida glabrata CCTCC M202019 was engineered for diacetyl production and a titer of $4.7 \mathrm{~g} \mathrm{~L}^{-1}$ was achieved, with a production yield of $0.10 \mathrm{~mol} \mathrm{~mol}^{-1}$ and a productivity of $0.07 \mathrm{~g} \mathrm{~L}^{-1} \mathrm{~h}^{-1}$ (Gao et al. 2014). For an industrial production 
of these compounds using these strains, the process productivity and yield should be further enhanced, since the glycolysis flux to diacetyl is low.

\section{Phenolic Aldehyde}

As previously described, vanillin is one of the most important flavors from the phenolic aldehyde class and it is mostly produced by bioconversion of phenolic compounds. Nevertheless, its production by de novo biosynthesis from cheap and more available carbon sources is much more attractive. Furthermore, the problem with potential off-taste which is associated with vanillin production using, e.g., eugenol or ferulic acid was also eliminated and contrary to the phenolic compounds, glucose is nontoxic to microorganisms (Evolva, personal communication). However, there is no evidence for direct bioconversion of glucose to vanillin in any naturally occurring microorganism. Li and Frost (1998) designed a pathway in recombinant E. coli for de novo biosynthesis of vanillic acid from glucose via the shikimate pathway. Nevertheless, the titers of vanillin detected are very low and this pathway requires the medium supplementation with costly cofactors and also isolated dehydrogenase. Thereafter, de novo biosynthesis of vanillin from glucose has been explored in Schizosaccharomyces pombe and Saccharomyces cerevisiae by a similar route, but introducing an aromatic carboxylic acid reductase gene to avoid the extracellular reaction, obtaining a vanillin production of around $45 \mathrm{mg} \mathrm{L}^{-1}$ (Hansen et al. 2009). Brochado et al. (2010) expressed a glycosyltransferase in the vanillin-producing $S$. cerevisiae strain in order to reduce the product toxicity. Compared with the previous work by Hansen and co-workers, the vanillin production increases in approximately fivefold (500 $\mathrm{mg} \mathrm{L}^{-1}$ ). More recently, Kunjapur et al. (2014) used an E. coli with reduced aromatic aldehyde reduction as a host for the biosynthesis of vanillin, and $119 \mathrm{mg} \mathrm{L}^{-1}$ vanillin can be produced from glucose. Ni et al. (2015) mimicking and assembling the natural pathway for vanillin production in plants in E. coli to synthesize vanillin from glucose and other substrates (L-tyrosine, xylose, and glycerol). The metabolically engineered strain produced $97.2 \mathrm{mg} \mathrm{L}^{-1}$ vanillin from 1-tyrosine, $19.3 \mathrm{mg} \mathrm{L}^{-1}$ from glucose, $13.3 \mathrm{mg} \mathrm{L}^{-1}$ from xylose, and $24.7 \mathrm{mg} \mathrm{L}^{-1}$ from glycerol. Nevertheless, the bioproduction of vanillin by de novo synthesis still has several challenges.

\section{Alcohols}

As previously described, 2-PE could be produced by bioconversion of L-Phe, as the sole nitrogen source, via the Ehrlich pathway, being this route the best and simple way to enhance the flavor production (ÄYräpää 1965; Etschmann et al. 2002). Nevertheless, the Ehrlich pathway uses L-Phe as a substrate to reach the maximum 2-PE concentration and substrates cheaper than L-Phe should be considered to achieve an economic production process (Kim et al. 2014a, b; Zhang et al. 2014). Through the shikimate pathway, 2-PE is obtained by de novo synthesis from carbohydrate precursors (Albertazzi et al. 1994; Carlquist et al. 2015; Etschmann et al. 2002). Nonetheless, de novo synthesis is inefficient and not economically viable, since glycolysis and the pentose-phosphate pathway are mainly used for cell growth, producing very low 2-PE concentrations (Carlquist et al. 2015; Etschmann et al. 2002). Celinska et al. (2013) compared the ability of different $Y$. lipolytica strains for 2-PE production from glucose, achieving concentrations of $0.2 \mathrm{~g} \mathrm{~L}^{-1}$. Recently, different strains were genetically engineered for overproduction of 2-PE from monosaccharide as a carbon source (Kang et al. 2014; Kim et al. 2014a, b; Zhang et al. 2014). Kim et al. (2014b) overexpressed the $A R O 10$ (codifies KDC) and $A D H 2$ (codifies ADH-alcohol dehydrogenase) genes of S. cerevisiae in $K$. marxianus BY25569. This genetically modified strain was able to produce $1.3 \mathrm{~g} \mathrm{~L}^{-1}$ of 2-PE from glucose without addition of L-Phe. Microbial production of 2-PE in engineered E. coli and Enterobacter sp. was also reported. Zhang et al. (2014) isolated and identified a new E. sp. CGMCC 5087 strain, which is able to produce 2-PE by de novo synthesis. The engineered strain produces $0.33 \mathrm{~g} \mathrm{~L}^{-1}$ of 2-PE in $12 \mathrm{~h}$. Kang et al. (2014) constructed a heterologous pathway to produce 2-PE directly from glucose in E. coli which allowed a 2-PE concentration of $0.26 \mathrm{~g} \mathrm{~L}^{-1}$.

\section{Conclusions}

A wide range of microbial strains are able to synthetize potentially valuable flavor and fragrance compounds and the examples presented here exemplify the power of microorganisms for its production. Despite the efforts that have been made, until now the yields of the products are too low to make the biotechnological process competitive and further studies are necessary to overcome the limitations found to date. The combination of optimization efforts on fermentation technologies and downstream processes represents a necessary step towards an economically feasible production of flavor and fragrance compounds.

Acknowledgments We would like to thank the Portuguese Foundation for Science and Technology (FCT) under the scope of the strategic funding of UID/BIO/04469 unit, COMPETE 2020 (POCI-01-0145FEDER-006684), and BiotecNorte operation (NORTE-01-0145FEDER-000004) funded by the European Regional Development Fund under the scope of Norte2020 - Programa Operacional Regional do Norte.

\section{Compliance with Ethical Standards}

Conflict of Interest The authors declare that they have no conflict of interest. 


\section{References}

Aguedo, M., Gomes, N., Garcia, E. E., Wache, Y., Mota, M., Teixeira, J. A., \& Belo, I. (2005). Decalactone production by Yarrowia lipolytica under increased $\mathrm{O} 2$ transfer rates. Biotechnology Letters, 27, 1617-1621. https://doi.org/10.1007/s10529-005-2517-z.

Albertazzi, E., Cardillo, R., Servi, S., \& Zucchi, G. (1994). Biogeneration of 2-phenylethanol and 2-phenylethylacetate important aroma components. Biotechnology Letters, 16, 491-496. https://doi.org/10. 1007/BF01023331.

Alonso-Gutierrez, J., Chan, R., Batth, T. S., Adams, P. D., Keasling, J. D., Petzold, C. J., \& Lee, T. S. (2013). Metabolic engineering of Escherichia coli for limonene and perillyl alcohol production. Metabolic Engineering, 19, 33-41. https://doi.org/10.1016/j. ymben.2013.05.004.

Angelov, A. D., \& Gotcheva, V. (2012). Biosynthesis of 2-phenylethanol by yeast fermentation. Scientific Works of UFT, 59, 490-495.

Ashengroph, M., \& Amini, J. (2017). Bioconversion of isoeugenol to vanillin and vanillic acid using the resting cells of Trichosporon asahii. Biotech, 7, 358. https://doi.org/10.1007/s13205-017-0998-9.

Ashengroph, M., Nahvi, I., Zarkesh-Esfahani, H., \& Momenbeik, F. (2012). Conversion of isoeugenol to vanillin by Psychrobacter sp. strain CSW4. Applied Biochemistry and Biotechnology, 166, 1-12. https://doi.org/10.1007/s12010-011-9397-6.

Ashengroph, M., Nahvi, I., \& Amini, J. (2013). Application of taguchi design and response surface methodology for improving conversion of isoeugenol into vanillin by resting cells of Psychrobacter sp. CSW4. Iranian Journal of Pharmaceutical Research, 12, 411-421.

ÄYräpää, T. (1965). The formation of phenethyl alcohol from 14Clabelled phenylalanine. Journal of the Institute of Brewing, 71, 341-347. https://doi.org/10.1002/j.2050-0416.1965.tb02068.x.

Barth, G. (2013). Yarrowia lipolytica: biotechnological applications. Springer Science \& Business Media.

Behrendorff, J. B., Vickers, C. E., Chrysanthopoulos, P., \& Nielsen, L. K. (2013). 2,2-Diphenyl-1-picrylhydrazyl as a screening tool for recombinant monoterpene biosynthesis. Microbial Cell Factories, 12, 76. https://doi.org/10.1186/1475-2859-12-76.

Belin, J. M., Bensoussan, M., \& Serrano-Carreon, L. (1992). Microbial biosynthesis for the production of food flavours. Trends Food Science Technology, 3, 11-14. https://doi.org/10.1016/09242244(92)90104-5.

Belo, I., Braga, A., Mesquita, D., Amaral, L., \& Ferreira, E. (2015). Comparison of aroma production from castor oil by Yarrowia lipolytica in airlift and STR bioreactors. Journal Biotechnology, 208, S14. https://doi.org/10.1016/j.jbiotec.2015.06.030.

Berger, R. G. (2007). Flavours and fragrances: chemistry, bioprocessing and sustainability. In Springer Berlin Heidelberg. Heidelberg: Berlin. https://doi.org/10.1007/978-3-540-49339-6.

Berger, R. G. (2009). Biotechnology of flavours-the next generation. Biotechnology Letters, 31, 1651-1659. https://doi.org/10.1007/ s10529-009-0083-5.

Bicas, J. L., Molina, G., Cavalcante Barros, F. F., \& Pastore, G. M. (2015). White biotechnology for sustainable chemistry. RSC Green Chemistry. https://doi.org/10.1039/9781782624080.

Bluemke, W., \& Schrader, J. (2001). Integrated bioprocess for enhanced production of natural flavors and fragrances by Ceratocystis moniliformis. Biomolecular Engineering, 17, 137-142. https://doi. org/10.1016/S1389-0344(01)00072-7.

Braga, A., \& Belo, I. (2013). Immobilization of Yarrowia lipolytica for aroma production from castor oil. Applied Biochemical Biotechnology, 169, 2202-2211. https://doi.org/10.1007/s12010013-0131-4.

Braga, A., \& Belo, I. (2015). Production of $\gamma$-decalactone by Yarrowia lipolytica: insights into experimental conditions and operating mode optimization. Journal Chemical Technology Biotechnology, 90, 559-565. https://doi.org/10.1002/jctb.4349.

Braga, A., Gomes, N., \& Belo, I. (2012). Lipase induction in Yarrowia lipolytica for castor oil hydrolysis and its effect on $\gamma$-decalactone production. Journal of the American Oil Chemists' Society, 89, 1041-1047. https://doi.org/10.1007/s11746-011-1987-5.

Braga, A., Gomes, N., Teixeira, J. A., \& Belo, I. (2013). Impact of lipasemediated hydrolysis of castor oil on $\gamma$-decalactone production by Yarrowia lipolytica. Journal of the American Oil Chemists' Society, 90, 1131-1137. https://doi.org/10.1007/s11746-013-2231-2.

Braga, A., Crutz-Le Coq, A. M., Dulermo, R., Nicaud, J. M., \& Belo, I. (2015a). Effect of POX genotype and Lip2p overexpression on lactone production and reconsumption by Yarrowia lipolytica using castor oil as substrate. Process Biochemistry, 50, 1357-1362. https://doi.org/10.1016/j.procbio.2015.05.019.

Braga, A., Mesquita, D. P., Amaral, A. L., Ferreira, E. C., \& Belo, I. (2015b). Aroma production by Yarrowia lipolytica in airlift and stirred tank bioreactors: differences in yeast metabolism and morphology. Biochemical Engineering Journal, 93, 55-62. https://doi. org/10.1016/j.bej.2014.09.006.

Brochado, A., Matos, C., Møller, B. L., Hansen, J., Mortensen, U. H., \& Patil, K. (2010). Improved vanillin production in baker's yeast through in silico design. Microbial Cell Factories, 9, 84. https:// doi.org/10.1186/1475-2859-9-84.

Burdock, G. A. (2010). Flavor ingredients (6th. ed.). CRC Press.

Cao, X., Lv, Y.-B., Chen, J., Imanaka, T., Wei, L.-J., \& Hua, Q. (2016). Metabolic engineering of oleaginous yeast Yarrowia lipolytica for limonene overproduction. Biotechnology for Biofuels, 9, 214. https://doi.org/10.1186/s13068-016-0626-7.

Caputi, L., \& Aprea, E. (2011). Use of terpenoids as natural flavouring compounds in food industry. Recent Patents on Food, Nutrition \& Agriculture, 3, 9-16. https://doi.org/10.2174/2212798411103010009.

Cardillo, R., Fuganti, C., Sacerdote, G., Barbeni, M., Cabella, P., Squarcia, F., (1990). Process for the microbiological production of gamma $(\mathrm{R})$ decanolide and gamma $(\mathrm{R})$ octanolide.

Carlquist, M., Gibson, B., Yuceer, Y. K., Paraskevopoulou, A., Sandell, M., Angelov, A. I., Gotcheva, V., Angelov, A. D., Etschmann, M., Billerbeck, G. M., \& de Lidén, G. (2015). Process engineering for bioflavour production with metabolically active yeasts - a mini-review. Yeast, 32, 123-143. https://doi.org/10.1002/yea.3058.

Carter, O. A., Peters, R. J., \& Croteau, R. (2003). Monoterpene biosynthesis pathway construction in Escherichia coli. Phytochemistry, 64, 425-433. https://doi.org/10.1016/S0031-9422(03)00204-8.

Celinska, E., Kubiak, P., Bialas, W., Dziadas, M., \& Grajek, W. (2013). Yarrowia lipolytica: the novel and promising 2-phenylethanol producer. Journal Industrial Microbiology Biotechnology, 40, 389 392. https://doi.org/10.1007/s10295-013-1240-3.

Cheetham, P. (2007). Advances in biochemical engineering/ biotechnology. https://doi.org/10.1007/BFb0102061.

Ciriminna, R., Lomeli-Rodriguez, M., Demma Carà, P., Lopez-Sanchez, J. A., \& Pagliaro, M. (2014). Limonene: a versatile chemical of the bioeconomy. Chemical Communications, 50, 15288-15296. https:// doi.org/10.1039/C4CC06147K.

Collins, R. P., \& Halim, A. F. (1972). Characterization of the major aroma constituent of the fungus Trichoderma viride. Journal of Agricultural and Food Chemistry, 20, 437-438. https://doi.org/10. 1021/jf60180a010.

Davies, F. K., Work, V. H., Beliaev, A. S., \& Posewitz, M. C. (2014). Engineering limonene and bisabolene production in wild type and a glycogen-deficient mutant of Synechococcus sp. PCC 7002. Frontiers in Bioengineering and Biotechnology, 2, 1-11. https:// doi.org/10.3389/fbioe.2014.00021.

Drawert, F., \& Barton, H. (1978). Biosynthesis of flavor compounds by microorganisms. 3. Production of monoterpenes by the yeast Kluyveromyces Lactis. Journal of Agricultural and Food Chemistry, 26, 765-766. https://doi.org/10.1021/jf60217a029. 
Dubal, S. A., Tilkari, Y. P., Momin, S. A., \& Borkar, I. V. (2008). Biotechnological routes in flavour industries. Review Literature and Arts of the Americas, 14, 15.

Duetz, W. A., Bouwmeester, H., Beilen, J. B., \& Witholt, B. (2003). Biotransformation of limonene by bacteria, fungi, yeasts, and plants. Applied Microbiology Biotechnology, 61, 269-277. https://doi.org/ 10.1007/s00253-003-1221-y.

Endrizzi, A., Awadé, A. C., \& Belin, J.-M. (1993). Presumptive involvement of methyl ricinoleate $\beta$-oxidation in the production of $\gamma$ decalactone by the yeast Pichia guilliermondii. FEMS Microbiology Letters, 114, 153-159. https://doi.org/10.1111/j. 1574-6968.1993.tb06566.x.

Engels, W. J. M., \& Visser, S. (1994). Isolation and comparative characterization of components that contribute to the flavour of different cheese types. Netherlands Milk Dairy Journal, 48, 127-140.

Escamilla-García, E., O'Riordan, S., Gomes, N., Aguedo, M., Belo, I., Teixeira, J., Belin, J.-M., \& Waché, Y. (2014). An air-lift biofilm reactor for the production of $\gamma$-decalactones by Yarrowia lipolytica. Process Biochemistry, 49, 1377-1382. https://doi.org/10.1016/j. procbio.2014.05.011.

Etschmann, M., Bluemke, W., Sell, D., \& Schrader, J. (2002). Biotechnological production of 2-phenylethanol. Applied Microbiology Biotechnology, 59, 1-8. https://doi.org/10.1007/ s00253-002-0992-x.

European Commission. (2008). Regulation (EC) No 1334/2008. Official Journal of the European Union L, 354(34), 34-50.

Eurovanille. (2017). Eurovanille - Vanilla Market Report. Vanilla Mark. Rep. URL http://www.eurovanille.com/en/our-mission/vanillamarket-report.html (accessed 8.4.17).

FDA. (2013). A food labeling guide. US Food Drug Adminstration, 132.

Fleige, C., Meyer, F., \& Steinbüchel, A. (2016). Metabolic engineering of the Actinomycete Amycolatopsis sp. strain ATCC 39116 towards enhanced production of natural vanillin. Applied Environmental Microbiology, 82, 3410-3419. https://doi.org/10.1128/AEM. 00802-16.

Furuya, T., Miura, M., Kuroiwa, M., \& Kino, K. (2015). High-yield production of vanillin from ferulic acid by a coenzymeindependent decarboxylase/oxygenase two-stage process. Nature Biotechnology, 32, 335-339. https://doi.org/10.1016/j.nbt.2015.03. 002 .

Furuya, T., Kuroiwa, M., \& Kino, K. (2017). Biotechnological production of vanillin using immobilized enzymes. Journal Biotechnology, 243, 25-28. https://doi.org/10.1016/j.jbiotec.2016.12.021.

Gallage, N. J., Hansen, E. H., Kannangara, R., Olsen, C. E., Motawia, M. S., Jørgensen, K., Holme, I., Hebelstrup, K., Grisoni, M., \& Møller, B. L. (2014). Vanillin formation from ferulic acid in Vanilla planifolia is catalysed by a single enzyme. Nature Communications, 5. https://doi.org/10.1038/ncomms5037.

Gao, X., Xu, N., Li, S., \& Liu, L. (2014). Metabolic engineering of Candida glabrata for diacetyl production. PLoS One, 9. https:// doi.org/10.1371/journal.pone.0089854.

Garcia, E. E., Belin, J. M., \& Wache, Y. (2007). Use of a Doehlert factorial design to investigate the effects of $\mathrm{pH}$ and aeration on the accumulation of lactones by Yarrowia lipolytica. Journal Applied Microbiology, 103, 1508-1515. https://doi.org/10.1111/j.13652672.2007.03379.x.

García, E. E., Aguedo, M., Gomes, N., Choquet, A., Belo, I., Teixeira, J. A., Belin, J.-M., \& Waché, Y. (2009). Production of 3-hydroxy- $\gamma$ decalactone, the precursor of two decenolides with flavouring properties, by the yeast Yarrowia lipolytica. Journal of Molecular Catalysis B: Enzymatic, 57, 22-26. https://doi.org/10.1016/j. molcatb.2008.06.010.

Gocho, S., Tabogami, N., Inagaki, M., Kawabata, C., \& Komai, T. (1995). Biotransformation of oleic acid to optically active $\gamma$ dodecalactone. Bioscience, Biotechnology, and Biochemistry, 59, 1571-1572. https://doi.org/10.1271/bbb.59.1571.
Gocho, S., Rumi, K., Tsuyoshi, K., (1998). Process for the production of $\delta$-decalactone.

Gomes, N., Aguedo, M., Teixeira, J., \& Belo, I. (2007). Oxygen mass transfer in a biphasic medium: influence on the biotransformation of methyl ricinoleate into $\gamma$-decalactone by the yeast Yarrowia lipolytica. Biochemical Engineering Journal, 35, 380-386. https:// doi.org/10.1016/j.bej.2007.02.002.

Gomes, N., Teixeira, J. A., \& Belo, I. (2012). Fed-batch versus batch cultures of Yarrowia lipolytica for $\gamma$-decalactone production from methyl ricinoleate. Biotechnology Letters, 34, 649-654. https://doi. org/10.1007/s10529-011-0824-0.

Groguenin, A., Waché, Y., Garcia, E. E., Aguedo, M., Husson, F., LeDall, M. T., Nicaud, J. M., \& Belin, J. M. (2004). Genetic engineering of the $\beta$-oxidation pathway in the yeast Yarrowia lipolytica to increase the production of aroma compounds. Journal of Molecular Catalysis B: Enzymatic, 28, 75-79. https://doi.org/10.1016/j. molcatb.2004.01.006.

Guo, T., Kong, J., Zhang, L., Zhang, C., \& Hu, S. (2012a). Fine tuning of the lactate and diacetyl production through promoter engineering in lactococcus lactis. PLoS One, 7. https://doi.org/10.1371/journal. pone. 0036296.

Guo, Y., Song, H., Wang, Z., \& Ding, Y. (2012b). Expression of POX2 gene and disruption of POX3 genes in the industrial Yarrowia lipolytica on the gamma-decalactone production. Microbiological Research, 167, 246-252. https://doi.org/10.1016/j.micres.2011.10. 003.

Guo, D., Zhang, L., Pan, H., \& Li, X. (2017). Metabolic engineering of Escherichia coli for production of 2-Phenylethylacetate from L-phenylalanine. Microbiologyopen, 1-5. https://doi.org/10.1002/mbo3. 486.

Hansen, E. H., Møller, B. L., Kock, G. R., Bünner, C. M., Kristensen, C., Jensen, O. R., Okkels, F. T., Olsen, C. E., Motawia, M. S., \& Hansen, J. (2009). De novo biosynthesis of vanillin in fission yeast (Schizosaccharomyces pombe) and baker's yeast (Saccharomyces cerevisiae). Applied and Environmental Microbiology, 75, 27652774. https://doi.org/10.1128/AEM.02681-08.

Hazelwood, L. A., Daran, J. M., Van Maris, A. J. A., Pronk, J. T., \& Dickinson, J. R. (2008). The Ehrlich pathway for fusel alcohol production: a century of research on Saccharomyces cerevisiae metabolism. Applied and Environmental Microbiology, 74, 2259-2266.

Hodges, A.W., Spreen, T.H., (2015). Economic impacts of citrus greening -(HLB) in Florida, 2006/07-2010/11. Univ. Florida IFAS Ext. 7-12.

Hua, D., \& Xu, P. (2011). Recent advances in biotechnological production of 2-phenylethanol. Biotechnology Advances, 29, 654-660. https://doi.org/10.1016/j.biotechadv.2011.05.001.

Huang, F.-C., \& Schwab, W. (2011). Cloning and characterization of a 9lipoxygenase gene induced by pathogen attack from Nicotiana benthamiana for biotechnological application. BMC Biotechnology, 11, 30. https://doi.org/10.1186/1472-6750-11-30.

Huang, Z., Dostal, L., \& Rosazza, J. P. N. (1993). Microbial transformations of ferulic acid by Saccharomyces cerevisiae and Pseudomonas fluorescens. Applied and Environmental Microbiology, 59, 22442250.

Hugenholtz, J., Kleerebezem, M., Delcour, J., De Vos, W., Hols, P., \& Starrenburg, M. (2000). Lactococcus lactis as a cell factory for highlevel diacetyl production. Applied and Environmental Microbiology, 66, 4112-4114. https://doi.org/10.1128/AEM.66.9.4112-4114. 2000.

Hui, Y. H. (2006). Handbook of food science, technology, and engineering, CRCNET books. Taylor \& Francis.

Jeon, I. J. (1994). Flavor chemistry of dairy lipids. Lipids Food Flavors, 558 SV, 14-196. https://doi.org/10.1021/bk-1994-0558.ch014.

Jiang, J. (1993). Identification of flavour volatile compounds produced by Kluyveromyces lactis. Biotechnology Techniques, 7, 863-866.

Jongedijk, E., Cankar, K., Ranzijn, J., van der Krol, S., Bouwmeester, H., \& Beekwilder, J. (2015). Capturing of the monoterpene olefin 
limonene produced in Saccharomyces cerevisiae. Yeast, 32, 159171. https://doi.org/10.1002/yea.3038.

Jongedijk, E., Cankar, K., Buchhaupt, M., Schrader, J., Bouwmeester, H., \& Beekwilder, J. (2016). Biotechnological production of limonene in microorganisms. Applied Biochemistry and Biotechnology. https://doi.org/10.1007/s00253-016-7337-7.

Kang, Z., Zhang, C., Du, G., \& Chen, J. (2014). Metabolic engineering of Escherichia coli for production of 2-phenylethanol from renewable glucose. Applied Biochemistry and Biotechnology, 172, 2012-2021. https://doi.org/10.1007/s12010-013-0659-3.

Kaur, B., \& Chakraborty, D. (2013). Biotechnological and molecular approaches for vanillin production: a review. Applied Biochemistry and Biotechnology. https://doi.org/10.1007/s12010-012-0066-1.

Kim, B., Cho, B. R., \& Hahn, J. S. (2014a). Metabolic engineering of Saccharomyces cerevisiae for the production of 2-phenylethanol via Ehrlich pathway. Biotechnoogy Bioenginering, 111, 115-124. https://doi.org/10.1002/bit.24993.

Kim, T. Y., Lee, S. W., \& Oh, M. K. (2014b). Biosynthesis of 2phenylethanol from glucose with genetically engineered Kluyveromyces marxianus. Enzyme Microbiology Technology, 6162, 44-47. https://doi.org/10.1016/j.enzmictec.2014.04.011.

Kiyota, H., Okuda, Y., Ito, M., Hirai, M. Y., \& Ikeuchi, M. (2014). Engineering of cyanobacteria for the photosynthetic production of limonene from CO2. Journal Biotechnology, 185, 1-7. https://doi. org/10.1016/j.jbiotec.2014.05.025.

Kunjapur, A. M., Tarasova, Y., \& Prather, K. L. J. (2014). Synthesis and accumulation of aromatic aldehydes in an engineered strain of Escherichia coli. Journal American Chemical Society, 136, 11644-11654. https://doi.org/10.1021/ja506664a.

Lange, B. M. (2015). Biosynthesis and biotechnology of high-value Pmenthane monoterpenes, including menthol, carvone, and limonene. IN Biotechnology of Isoprenoids, 148, 319-353. https://doi. org/10.1007/10_2014_289.

Li, K., \& Frost, J. W. (1998). Synthesis of vanillin from glucose. Journal of the American Chemical Society, 120, 10545-10546. https://doi. org/10.1021/ja9817747.

Longo, M. A., \& Sanromán, M. A. (2006). Production of food aroma compounds: microbial and enzymatic methodologies. Food Technology and Biotechnology, 44, 335-353.

Maróstica, M. R., \& Pastore, G. M. (2007). Biotransformação de limoneno: Uma revisão das principais rotas metabólicas. Quimica Nova. https://doi.org/10.1590/S0100-40422007000200027.

Monnet, C., Aymes, F., \& Corrieu, G. (2000). Diacetyl and alphaacetolactate overproduction by Lactococcus lactis subsp. lactis biovar diacetylactis mutants that are deficient in alpha-acetolactate decarboxylase and have a low lactate dehydrogenase activity. Applied Microbiology Biotechnology, 66, 5518-5520. https://doi. org/10.1128/aem.66.12.5518-5520.2000.

Nadal, I., Rico, J., Pérez-Martínez, G., Yebra, M. J., \& Monedero, V. (2009). Diacetyl and acetoin production from whey permeate using engineered lactobacillus casei. Journal Industrial Microbiology Biotechnolology, 36, 1233-1237. https://doi.org/10.1007/s10295009-0617-9.

Nelson, D. L., Cox, M. M. (2008). Lehninger principles of biochemistry 5th ed. Book. https://doi.org/10.2307/1309148.

Ni, J., Tao, F., Du, H., \& Xu, P. (2015). Mimicking a natural pathway for de novo biosynthesis: natural vanillin production from accessible carbon sources. Scientific Reports, 5, 13670. https://doi.org/10. 1038/srep13670.

Pagot, Y., Endrizzi, A., Nicaud, J. M., \& Belin, J. M. (1997). Utilization of an auxotrophic strain of the yeast Yarrowia lipolytica to improve gamma-decalactone production yields. Letters Applied Microbiology, 25, 113-116.

Pagot, Y., Le Clainche, A., Nicaud, J.-M., Wache, Y., \& Belin, J.-M. (1998). Peroxisomal $\beta$-oxidation activities and $\gamma$-decalactone production by the yeast Yarrowia lipolytica. Applied Microbiology
Biotechnology, 49, 295-300. https://doi.org/10.1007/ s002530051172.

Papagianni, M., Avramidis, N., \& Filiousis, G. (2007). Investigating the relationship between the specific glucose uptake rate and nisin production in aerobic batch and fed-batch glucostat cultures of Lactococcus lactis. Enzyme Microbial Technology, 40, 1557-1563. https://doi.org/10.1016/j.enzmictec.2006.10.035.

Patton, S. (1950). The methyl ketones of blue cheese and their relation to its flavor. Journal of Dairy Science, 33, 680-684. https://doi.org/10. 3168/jds.S0022-0302(50)91954-0.

Priefert, H., Rabenhorst, J., \& Steinbüchel, A. (2001). Biotechnological production of vanillin. Applied Microbiology Biotechnology. https:// doi.org/10.1007/s002530100687.

Ramachandra Rao, S., \& Ravishankar, G. a. (2000). Vanilla flavour: production by conventional and biotechnological routes. Journal of the Science of Food and Agriculture, 80, 289-304. https://doi. org/10.1002/1097-0010(200002)80:3<289::AID-JSFA543>3.0. $\mathrm{CO} ; 2-2$.

Rohdich, F., Bacher, A., \& Eisenreich, W. (2005). Isoprenoid biosynthetic pathways as anti-infective drug targets. Biochemical Society Transactions, 33, 785-791. https://doi.org/10.1042/BST0330785.

Rong, S., Wang, M., Yang, S., Li, Q., Guan, S., Cai, B., \& Zhang, S. (2017a). Improvement in lactone production from biotransformation of ricinoleic acid based on the porous starch delivery system. Journal Chemical Technology Biotechnology. https://doi.org/10. $1002 /$ jctb.5481.

Rong, S., Yang, S., Li, Q., Cai, B., Guan, S., Wang, J., Zhou, Y., \& Chen, Y. (2017b). Improvement of $\gamma$-decalactone production by stimulating the import of ricinoleic acid and suppressing the degradation of $\gamma$-decalactone in Saccharomyces cerevisiae. Biocatalalysis Biotransformation, 35, 96-102. https://doi.org/10.1080/10242422. 2017.1289182.

Schrader, J., Etschmann, M. M. W., Sell, D., Hilmer, J. M., \& Rabenhorst, J. (2004). Applied biocatalysis for the synthesis of natural flavour compounds-current industrial processes and future prospects. Biotechnology Letters, 26, 463-472.

Sinha, A. K., Sharma, U. K., \& Sharma, N. (2008). A comprehensive review on vanilla flavor: extraction, isolation and quantification of vanillin and others constituents. International Journal of Food Sciences and Nutrition. https://doi.org/10.1080/09687630701539350.

Soares, G. P. A., Souza, K. S. T., Vilela, L. F., Schwan, R. F., \& Dias, D. R. (2017). $\gamma$-Decalactone production by Yarrowia lipolytica and Lindnera saturnus in crude glycerol. Preparative Biochemistry and Biotechnology, 47, 633-637. https://doi.org/10.1080/ 10826068.2017.1286601.

Surburg, H., Panten, J., Bauer, K., \& John Wiley \& Sons. (2006). Common fragrance and flavor materials: preparation, properties and uses. Wiley-VCH.

Tilay, A., Bule, M., \& Annapure, U. (2010). Production of biovanillin by one-step biotransformation using fungus Pycnoporous cinnabarinus. Journal of Agricultural and Food Chemistry, 58, 4401-4405. https://doi.org/10.1021/jf904141u.

Vandamme, E. J. (2003). Bioflavours and fragrances via fungi and their enzymes. In Fungal Diversity, 13, 153-166.

Vandamme, E. J., \& Soetaert, W. (2002). Bioflavours and fragrances via fermentation and biocatalysis. Journal Chemical Technology Biotechnology, 77, 1323-1332. https://doi.org/10.1002/jctb.722.

Waché, Y., Aguedo, M., Choquet, A., Gatfield, I. L., Nicaud, J.-M., \& Belin, J.-M. (2001). Role of $\beta$-oxidation enzymes in $\gamma$-decalactone production by the yeast Yarrowia lipolytica. Applied Environmental Microbiology, 67, 5700-5704. https://doi.org/10.1128/AEM.67.12. 5700-5704.2001.

Waché, Y., Aguedo, M., LeDall, M. T., Nicaud, J. M., \& Belin, J. M. (2002). Optimization of Yarrowia lipolytica's $\beta$-oxidation pathway for $\gamma$-decalactone production. Journal of Molecular Catalysis B: 
Enzymatic, 347-351. https://doi.org/10.1016/S1381-1177(02) 00185-6.

Walton, N. J., Mayer, M. J., \& Narbad, A. (2003). Vanillin. Phytochemistry. https://doi.org/10.1016/S0031-9422(03)00149-3.

Wang, Z., Bai, X., Guo, X., \& He, X. (2017). Regulation of crucial enzymes and transcription factors on 2-phenylethanol biosynthesis via Ehrlich pathway in Saccharomyces cerevisiae. Journal Industrial Microbiology Biotechnology, 44, 129-139. https://doi. org/10.1007/s10295-016-1852-5.

Willrodt, C., David, C., Cornelissen, S., Bühler, B., Julsing, M. K., \& Schmid, A. (2014). Engineering the productivity of recombinant Escherichia coli for limonene formation from glycerol in minimal media. Biotechnology Journal, 9, 1000-1012. https://doi.org/10. 1002/biot.201400023.

Withers, S. T., \& Keasling, J. D. (2007). Biosynthesis and engineering of isoprenoid small molecules. Applied Microbiology and Biotechnology. https://doi.org/10.1007/s00253-006-0593-1.

$\mathrm{Xu}$, P., Hua, D., \& Ma, C. (2007). Microbial transformation of propenylbenzenes for natural flavour production. Trends Biotechnology, 25, 571-576. https://doi.org/10.1016/j.tibtech.2007. 08.011 .
Zhang, H., Cao, M., Jiang, X., Zou, H., Wang, C., Xu, X., \& Xian, M. (2014). De-novo synthesis of 2-phenylethanol by Enterobacter sp. CGMCC 5087. BMC Biotechnology, 14, 30. https://doi.org/10. 1186/1472-6750-14-30.

Zhang, L., Zhang, Y., Liu, Q., Meng, L., Hu, M., Lv, M., Li, K., Gao, C., Xu, P., \& Ma, C. (2015). Production of diacetyl by metabolically engineered Enterobacter cloacae. Scientific Reports, 5, 9033. https://doi.org/10.1038/srep09033.

Zhao, L.-Q., Sun, Z.-H., Zheng, P., \& Zhu, L.-L. (2005). Biotransformation of isoeugenol to vanillin by a novel strain of Bacillus fusiformis. Biotechnology Letters, 27, 1505-1509. https:// doi.org/10.1007/s10529-005-1466-x.

Zhao, L., Bao, Y., Wang, J., Liu, B., \& An, L. (2009). Optimization and mechanism of diacetyl accumulation by Enterobacter aerogenes mutant UV-3. World Journal Microbiology Biotechnology, 25, 5764. https://doi.org/10.1007/s11274-008-9862-8.

Zhao, Y., Xu, Y., \& Jiang, C. (2015). Efficient biosynthesis of $\gamma$ decalactone in ionic liquids by immobilized whole cells of Yarrowia lipolytica G3-3.21 on attapulgite. Bioprocess and Biosystems Engineering, 38, 2045-2052. https://doi.org/10.1007/ s00449-015-1431-6. 